\title{
Evaluating the Correlation between Overjet and Skeletal Parameters Using DVT
}

\author{
Luca Lombardo, Chiara Sgarbanti, Antonio Guarneri, and Giuseppe Siciliani
}

Postgraduate School of Orthodontics, University of Ferrara, Via Montebello 31, 44100 Ferrara, Italy

Correspondence should be addressed to Luca Lombardo, dott.lulombardo@gmail.com

Received 19 March 2012; Revised 26 May 2012; Accepted 14 June 2012

Academic Editor: Marcelo G. P. Cavalcanti

Copyright (๑) 2012 Luca Lombardo et al. This is an open access article distributed under the Creative Commons Attribution License, which permits unrestricted use, distribution, and reproduction in any medium, provided the original work is properly cited.

\begin{abstract}
Aim. To evaluate the degree of correlation between a dental parameter of immediate clinical relevance (overjet) with skeletal (ANB angle) and dentoskeletal parameters such as the IMPA angle and upper incisor-bispinal angle. Materials and Methods. A sample of 42 subjects, all in complete permanent dentition and without a history of orthodontic treatment or systemic pathologies, was subdivided into 2 groups: group 1 consisted of 25 subjects with ANB angle $0^{\circ}-4^{\circ}$ (skeletal class I), and group 2 was made up of 17 subjects with ANB angle $>4^{\circ}$ (skeletal class II). Each subject underwent cone-beam computed tomography (CBCT). For each right and left CBCT, the following parameters were measured: (1) ANB, (2) OJ (overjet), (3) IMPA angle, and (4) upper incisorbispinal angle (U1/ANS-PNS). Results. Analysis of the entire sample revealed that both right and left overjets were correlated in a statistically significant fashion $(P<0.001)$ with ANB. No correlation between overjet and IMPA emerged, while a weak correlation between overjet and the left U1-bispinal plane was ascertained. Conclusions. Overjet may be a reliable predictor of ANB, and to a lesser extent the U1-bispinal plane, particularly in skeletal class II.
\end{abstract}

\section{Introduction}

In order to formulate a correct orthodontic diagnosis, accurate and thorough documentation of anamnesis, intra- and extraoral clinical examinations, model analysis, radiographic analysis, and cephalometric and photographic studies is required [1].

In diagnosis, it is particularly important to obtain an accurate measurement of overjet, as this describes the sagittal relationship between the upper and lower central incisors. After crowding, excessive protrusion of the upper central incisors is the most frequent cause of malocclusion in Caucasian subjects [2]. It is generally accepted that increased overjet is due to a growth deficit of the jaw rather than poor positioning of the dental elements but no significant data regarding this has been published as yet [3].

$A N B$ angle on the other hand indicates a skeletal discrepancy between the jaws, which must be brought back into harmony during treatment. This value, as well as being influenced by the anteroposterior relationship between the jaws, is not always an indicator of a real imbalance in the patient as it may also be influenced by the vertical height of the face or the position of the nasion [4]. However, consideration of another parameter, the inclination of the upper and lower incisors with respect to the osseous base, may help to establish the correct relative protrusion of the teeth [5].

Thus, a relationship between overjet and skeletal parameters is evident, but the challenge in planning adequate treatment can be understanding how to interpret and correctly correlate dental and skeletal values.

In this study, the following parameters were considered: overjet as the dental parameter, ANB as the skeletal parameter, and inclination of the incisors with respect to the osseous base, that is, the IMPA angle and the U1-bispinal plane (ANS/PNS) angle, as the dentoskeletal parameters.

Values corresponding to these parameters were obtained from analysing of digital volumetric tomographs acquired via CBCT (cone-beam computed tomography). This system allows us to procure images suitable for detailed study of a patient's anatomy and to examine the structures present at a high level of accuracy and precision [6]. 
The aim of this study was therefore to evaluate the degree to which a dental parameter of immediate clinical relevance (overjet) correlates to skeletal (ANB) and dentoskeletal (IMPA angle and U1-bispinal plane angle) parameters to provide a potential diagnostic aid.

\section{Materials and Methods}

From a sample of 73 subjects aged between 18 and 40 years, 42 subjects (25 females, 17 males) all in integral permanent dentition, unaffected by maxillofacial syndromes or evident trauma, lacking a history of orthodontic or surgical treatment, and without insalubrious habits were selected; furthermore, all subjects with metallic prostheses in the incisal region were excluded, as these devices are known to provoke scattering phenomena, as were subjects with ANB angle $<0^{\circ}$, as these subjects were not statistically significant in number. The sample was further divided into 2 groups: group 1 comprising 25 subjects in skeletal class I with ANB angle $0^{\circ}-4^{\circ}$, and group 2 constituted by 17 subjects in skeletal class II, with ANB angle $x>4^{\circ}$.

CBCT (cone-beam computed tomography) was performed on each subject using the NewTom 3G Volume Scanner (QRsr1, Verona), which employs a conical beam Xray emission technique that markedly reduces the quantity of radiation absorbed by the patient, to obtain the images. The settings applied were FOV 12 inches, $110 \mathrm{kV}$ (AP-LL), $2.00 \mathrm{~mA}$ (AP), $1.00 \mathrm{~mA}$ (LL), exposure time $5.4 \mathrm{~s}$, and section thickness $0.50 \mathrm{~mm}$.

Each CBCT (cone-beam computed tomography) was then analysed via NNT NewTom 3G software by an orthodontist with experience in using this programme.

For each left and right CBCT (cone-beam computed tomography) the following parameters were measured:

(i) ANB angle: anterior-posterior relationship of the maxilla with the mandible is measured in degrees,

(ii) overjet $(\mathrm{OJ})$ : sagittal relationship between the upper and lower central incisors is measured in millimeter,

(iii) IMPA angle: inclination of the lower incisor with respect to the mandibular plane defined as axis between gonion (Go) and menton $(\mathrm{Me})$ is measured in degrees,

(iv) U1-bispinal plane angle: inclination of the upper incisor with respect to the bispinal plane. The bispinal plane is defined as axis between the anterior nasal spine (ANS) and the posterior nasal spine (PNS) is measured in degrees.

All CBCT (cone-beam computed tomography) measurements were subsequently repeated by the same operator in order to permit reliable evaluation of the data found. Moreover, to quantify the degree of error, an MSA (Measurement Systems Analysis) was performed which utilises a Dahlberg's $d$ test, whose formula is $s^{2}=\sum d^{2} / 2 n$.

Dahlberg's test revealed the absence of statistically significant systematic errors in measurement. However, the systematic error was subsequently calculated using Student's
TABLe 1: Dahlberg's $d$ test: $s^{2}=\sum d^{2} / 2 n$ applied to the entire sample and repeated twice revealed no statistically significant systematic measurement errors. The systematic error calculated via Student's $t$-test for paired data yielded a significance level of 0.05 .

\begin{tabular}{lcc}
\hline Variable & Dahlberg's test & $P$ value \\
\hline ANB & 0.11905 & 0.950475 \\
IMPA-r & 0.53631 & 0.369756 \\
11/SNA-SNP & 0.64845 & 0.165493 \\
OJ-r & 0.00690 & 0.065285 \\
IMPA-1 & 1.49048 & 0.673221 \\
OJ-1 & 0.00417 & 0.617962 \\
21/SNA-SNP & 1.35000 & 0.098852 \\
\hline
\end{tabular}

$t$-test for paired data and yielded a significance level of 0.05 (Table 1).

To measure the ANB angle, a secondary reconstruction was performed for each CBCT wherein 3D MIP (3D maximum intensity projection) images were created; this format was selected as it consents application of units of measurement to the image to be exported.

To measure overjet and IMPA, right and left panoramic sections in which the relationship between the upper and lower incisors was clear were taken, permitting identification of the menton and right and left Go for calculation of the IMPA and consenting the degree of overjet to be established.

Finally, in order to measure the inclination of the right and left upper central incisors with respect to the bispinal plane, a secondary reconstruction of each CBCT (conebeam computed tomography) was obtained so as to procure sagittal sections of the upper jaw perpendicular to the line passing through the centre of each radicular canal. For each of these sections, the angle between the incisor axis and the bispinal plane, the latter passing through the anterior and the posterior nasal spines, was calculated (Figure 1).

\section{Statistical Analysis}

The data obtained (see Table 2) were subsequently analysed statistically using multiple linear regression in order to evaluate the existence of a statistically significant correlation between dental and skeletal parameters, both in the sample as a whole and for the disparate groups 1 (ANB angle: $0^{\circ}-4^{\circ}$ ) and 2 (ANB angle $>4^{\circ}$ ).

Two distinct analyses were performed: the first to analyse the entire sample and the second to evaluate separately group 1 (ANB angle: $0^{\circ}-4^{\circ} \mathrm{mm}$ ) and group 2 (ANB angle $>4^{\circ}$ ). In both analyses, first $\mathrm{OJ}$ right then $\mathrm{OJ}$ left were assumed as dependent variables.

\section{Results}

4.1. Analysis of the Entire Sample. OJ right was equated to ANB, IMPA right, 11/ANS-PNS, and 21/ANS-PNS.

In $a$ distribution analysis, only the dependent variable $\mathrm{OJ}$ right was found to have an altered trend. However, given the 


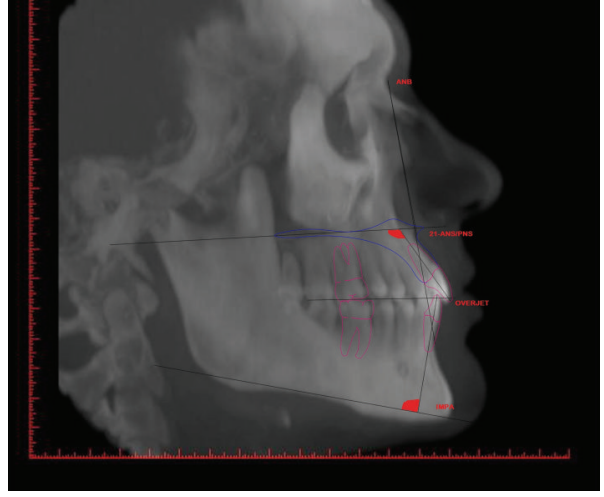

(a)

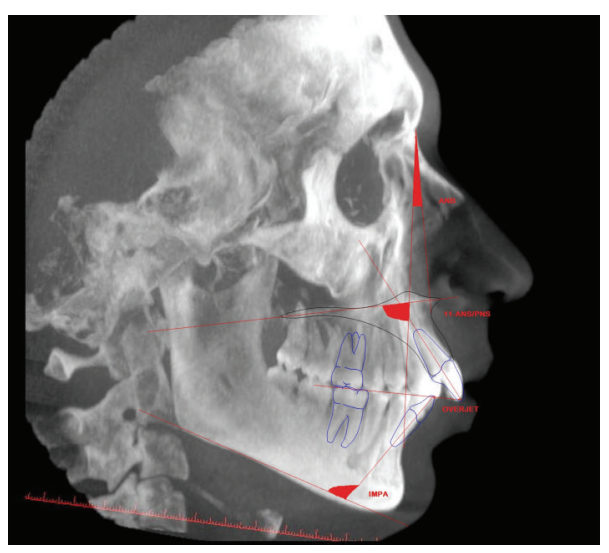

(c)

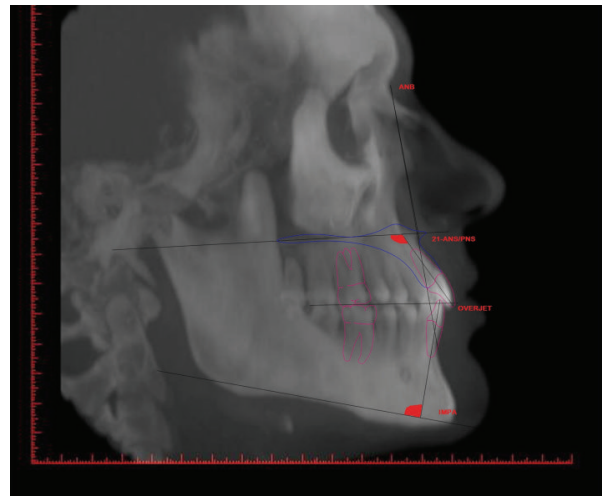

(b)

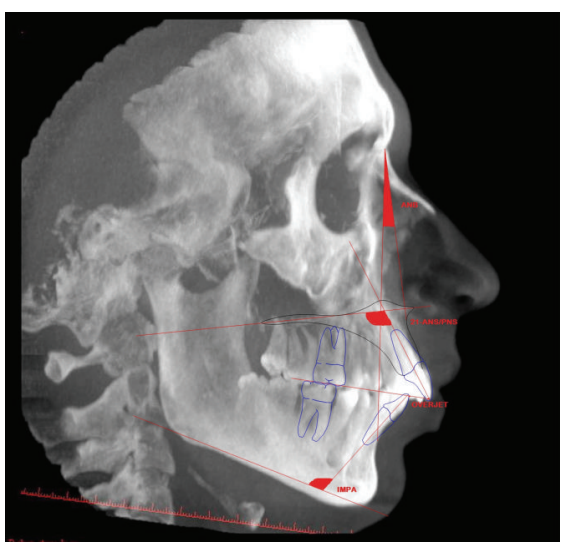

(d)

Figure 1: Examples of CBCT right and left of two subjects. The first two figures belong to a subject with ANB $0^{\circ}-4^{\circ}$ (skeletal class I), the second two to a subject with ANB $>4^{\circ}$ (skeletal class II). In the images, axes and angles like ANB, IMPA, U1-bispinal plane, and overjet were drawn to explain the aim of this work. In the research, each parameter was analysed via NNT NewTom $3 \mathrm{G}$ software using particularly secondary reconstruction.

numerosity higher than 30, it was possible to hypothesise that the distribution of $\mathrm{OJ}$ right also tends towards the normal.

At this point, multiple linear regression analysis was carried out: first the correlation indices were applied and $\mathrm{OJ}$ right was found to correlate positively, to a statistically significant degree, with ANB $(R=0.4872 ; P=0.001)$; then a multiple linear regression test revealed that $O J$ right only correlated in a statistically significant manner with ANB and 21/ANS-PNS (Table 3). Eliminating the two variables found to be nonsignificant, the following expression was formulated for the final model:

$$
\mathrm{OJ} \text { right }=-10.56+0.60 * \mathrm{ANB}+0.10 * 21 / \mathrm{ANS}-\mathrm{PNS} \text {, }
$$

with ANB $(P=0.000060)$ and $21 /$ ANS-PNS $(P=0.003187)$ being highly significant, as was the intercept $(P=0.007069)$. Fisher's goodness-of-fit index also yielded a highly significant value $(P=0.00006)$. Nevertheless, the linear determination index was fairly low $\left(R^{2}=0.391\right)$.

Subsequently OJ left was considered as the dependent variable and equated with ANB, IMPA left, 11/ANS-PNS, and 21/ANS-PNS. Via distribution analysis, the only variable found to have abnormal distribution was the dependent $\mathrm{OJ}$ left itself. However, given the numerosity higher than 30 , it was possible to hypothesise that the distribution of $\mathrm{OJ}$ left also tends towards the normal.

Multiple linear regression analysis was also carried out for this variable: the correlation indices revealed that OJ left had a positive, statistically significant correlation with ANB ( $R=0.4872 ; P=0.001)$, and the multiple linear regression test showed that OJ left is correlated in a statistically significant manner with ANB and 21/ANS-PNS (Table 4). Elimination of the variable found to be nonsignificant (IMPA LEFT) yielded a final model which can be expressed as

OJ $\mathrm{LEFT}=-10.17+0.56 * \mathrm{ANB}+0.10 * 21 / \mathrm{ANS}-\mathrm{PNS}$,

with $\operatorname{ANB}(P=0.000596), 21 /$ ANS-PNS $(P=0.009593)$, and the intercept $(P=0.002)$ being highly significant. A highly significant value was also obtained upon application of Fisher's goodness-of-fit test $(P=0.0007)$, although the linear determination index was low $\left(R^{2}=0.313\right)$. 
TABLE 2: Initial measurements of the entire sample revealed. In bold ANB $>4$, in regular font ANB 0-4.

\begin{tabular}{|c|c|c|c|c|c|c|c|}
\hline Subject & ANB & IMPA-r & 11/SNA-SNP & OJ-r & IMPA-1 & OJ-1 & 21/SNA-SNP \\
\hline 1 & 7.9 & 93.5 & 95.6 & 2.3 & 96.2 & 2.6 & 96.4 \\
\hline 2 & 1.8 & 86 & 97.6 & 0.8 & 81.5 & 0.8 & 96.5 \\
\hline 3 & 2 & 85.6 & 93.7 & 2.1 & 82.5 & 2.1 & 100.1 \\
\hline 4 & 1.7 & 92.2 & 105.7 & 1.7 & 97.8 & 1.3 & 112.9 \\
\hline 5 & 4.8 & 94.5 & 103.1 & 2.1 & 94.2 & 1.7 & 102.9 \\
\hline 6 & 5.8 & 99.8 & 103.4 & 1.3 & 98.8 & 1.7 & 100.6 \\
\hline 7 & 7.5 & 91.7 & 101.5 & 1.7 & 91.3 & 1.7 & 93.2 \\
\hline 8 & 4.9 & 96.5 & 106.7 & 2.1 & 96.6 & 2.1 & 106.9 \\
\hline 9 & 2.5 & 94.3 & 110.9 & 2.6 & 94.4 & 2.1 & 110.6 \\
\hline 10 & 3.3 & 98.8 & 100.3 & 3.5 & 99.5 & 3.5 & 104 \\
\hline 11 & 3.8 & 94.6 & 100 & 1.7 & 98.8 & 1.7 & 100.5 \\
\hline 12 & 1.5 & 87.8 & 100 & 0.8 & 90.5 & 0.8 & 95.3 \\
\hline 13 & 4.5 & 98.8 & 106.5 & 2.6 & 94.8 & 2.6 & 100.7 \\
\hline 14 & 5 & 92.7 & 108.4 & 4.2 & 91 & 2.9 & 96.4 \\
\hline 15 & 5.3 & 98.3 & 122 & 2.1 & 99 & 1.7 & 118.3 \\
\hline 16 & 1.9 & 93.3 & 110.3 & 2.5 & 97.1 & 2.5 & 105.7 \\
\hline 17 & 3.1 & 97.2 & 119.3 & 4.2 & 93 & 4.2 & 118.8 \\
\hline 18 & 4.3 & 104.7 & 107.7 & 2.9 & 98.3 & 2.9 & 110.3 \\
\hline 19 & 5.8 & 108.5 & 106.7 & 2.5 & 106.2 & 2.1 & 98.9 \\
\hline 20 & 3.6 & 99.1 & 108.9 & 3.4 & 97.7 & 3.4 & 109.4 \\
\hline 21 & 3.9 & 99.5 & 114.9 & 2.1 & 97.2 & 1.7 & 116.6 \\
\hline 22 & 3.5 & 110.6 & 114 & 2.5 & 109 & 2.1 & 112.6 \\
\hline 23 & 3.6 & 90.9 & 104.4 & 4.6 & 96 & 7.2 & 103.9 \\
\hline 24 & 6.1 & 108.4 & 99 & 4.2 & 107.4 & 4.2 & 100.7 \\
\hline 25 & 2.2 & 100 & 116.9 & 4 & 106.7 & 0 & 112.1 \\
\hline 26 & 4.5 & 114.7 & 107.9 & 4.2 & 113.9 & 3 & 111.5 \\
\hline 27 & 2.7 & 107.6 & 119.5 & 2.9 & 103.1 & 4.6 & 114.1 \\
\hline 28 & 3.9 & 95.2 & 100.8 & 2.1 & 95.7 & 2.9 & 102.6 \\
\hline 29 & 9.2 & 101.2 & 106.4 & 10.5 & 99.3 & 10 & 108.7 \\
\hline 30 & 7.8 & 95.5 & 117.9 & 8.4 & 92.3 & 8.4 & 112.3 \\
\hline 31 & 2.9 & 101.7 & 113.4 & 1.7 & 103.6 & 1.7 & 117.1 \\
\hline 32 & 3.4 & 98 & 107.5 & 1.7 & 101.3 & 2.1 & 109.7 \\
\hline 33 & 1.9 & 100.1 & 129.3 & 2.1 & 100.3 & 1.7 & 116.9 \\
\hline 34 & 1.8 & 104.7 & 104.6 & 2.5 & 105.7 & 2.5 & 110.7 \\
\hline 35 & 2.2 & 97 & 103.7 & 4.6 & 96.1 & 5 & 112.5 \\
\hline 36 & 4.2 & 92.4 & 118.4 & 6.7 & 94 & 7.1 & 125.4 \\
\hline 37 & 1.9 & 101.9 & 104.2 & 2.9 & 99.1 & 2.5 & 104.2 \\
\hline 38 & 3.4 & 100.5 & 117 & 2.1 & 103.4 & 2.1 & 113.4 \\
\hline 39 & 3.2 & 100.5 & 112.7 & 1.3 & 100.7 & 1.3 & 101.7 \\
\hline 40 & 2.5 & 91.4 & 107.9 & 4.3 & 89.3 & 4.9 & 109.7 \\
\hline 41 & 4 & 97.6 & 101.1 & 3.4 & 95.8 & 3.4 & 103 \\
\hline 42 & 5.4 & 104.2 & 97.8 & 2.1 & 101.8 & 2.1 & 105.3 \\
\hline
\end{tabular}

4.2. Analysis of the 2 Groups. As per the entire sample, a linear regression model was employed for each group.

In group 1 (ANB $0<x<4)$, neither of the linear correlation indices $\mathrm{OJ}$ right and $\mathrm{OJ}$ left were found to be correlated to any of the predictor variables. Furthermore, multiple linear regression analysis for OJ right (Table 5) and OJ left (Table 6) showed that no independent variable was significant and, therefore, no model could be constructed.
In group 2 (ANB > 4), analysis of the correlation indices yielded similar results. In fact, neither OJ right nor OJ left were found to correlate significantly with any of the predictor variables, although multiple linear regression analysis applied to OJ right revealed a statistically significant correlation between this parameter and ANB (Table 7). However, after elimination of the nonsignificant variables, regression analysis showed that no model could be constructed. 
TABLE 3: Entire sample (42 subjects): linear regression results for OJ-r; only ANB and 21/SNA-SNP were found to be statistically significant. The systematic error calculated via Student's $t$-test for paired data yielded a significance level of 0.05 ; ns: nonsignificant.

\begin{tabular}{lcc}
\hline & $B$ & $P$ level \\
\hline ANB & 0.64 & 0.000034 \\
IMPA DX & -0.04 & $\mathrm{~ns}$ \\
$11 /$ SNA-SNP & -0.05 & $\mathrm{~ns}$ \\
21/SNA-SNP & 0.16 & 0.004144 \\
$R^{2}=0.42954353 ; R^{2}$ correct $=0.36787256$ & & \\
\hline
\end{tabular}

TABLE 4: Entire sample (42 subjects): linear regression results for OJ-l; only ANB and 21/SNA-SNP were found to be statistically significant. The systematic error calculated via Student's $t$-test for paired data yielded a significance level of 0.05 ; ns: non significant (Student's $t$-test).

\begin{tabular}{lcc}
\hline & $B$ & $P$ level \\
\hline ANB & 0.62 & 0.000144 \\
11/SNA-SNP & -0.06 & $\mathrm{~ns}$ \\
IMPA SX & -0.08 & $\mathrm{~ns}$ \\
21/SNA-SNP & 0.18 & 0.003007 \\
$R^{2}=0.40149186 ; R^{2}$ correct $=0.33678828$ & & \\
\hline
\end{tabular}

TABLE 5: Group 1 (25 subjects): linear regression results OJ-r; no independent variable was found to be statistically significant in the multivariate linear regression model. The systematic error calculated via Student's $t$-test for paired data yielded a significance level of 0.05; ns: non significant (Student's $t$-test).

\begin{tabular}{lcc}
\hline & $B$ & $P$ level \\
\hline ANB & 0.30 & $\mathrm{~ns}$ \\
IMPA DX & -0.02 & $\mathrm{~ns}$ \\
$11 /$ SNA-SNP & -0.07 & $\mathrm{~ns}$ \\
$21 /$ SNA-SNP & 0.12 & $\mathrm{~ns}$ \\
$R^{2}=0.21405906 ; R^{2}$ correct $=0.05687087$ & & \\
\hline
\end{tabular}

TABle 6: Group 1 (25 subjects): linear regression results for OJ1 ; no independent variable was found to be statistically significant in the multivariate linear regression model. The systematic error calculated via Student's $t$-test for paired data yielded a significance level of 0.05; ns: non significant (Student's $t$-test).

\begin{tabular}{lcc}
\hline & $B$ & $P$ level \\
\hline ANB & 0.65 & $\mathrm{~ns}$ \\
$11 /$ SNA-SNP & -0.06 & $\mathrm{~ns}$ \\
IMPA SX & -0.06 & $\mathrm{~ns}$ \\
$21 /$ SNA-SNP & 0.11 & $\mathrm{~ns}$ \\
$R^{2}=0.18725388 ; R^{2}$ correct $=0.02470466$ & & \\
\hline
\end{tabular}

Linear regression analysis of OJ left, on the other hand, gave statistically significant values for ANB and 21/ANS-PNS (Table 8 ). Thus, eliminating the two nonsignificant values, a definitive final model was obtained in which ANB $(P=$ $0.002990)$ and $21 /$ ANS-PNS $(P=0.003550)$ were highly
TABLE 7: Group 2 (17 subjects): linear regression results for OJ$\mathrm{r}$ : only the ANB variable was found to be statistically significant. The systematic error calculated via Student's $t$-test for paired data yielded a significance level of 0.05 ; ns: non significant (Student's $t$ test).

\begin{tabular}{lcc}
\hline & $B$ & $P$ level \\
\hline ANB & 1.02 & 0.011533 \\
IMPA DX & 0.02 & ns \\
$11 /$ SNA-SNP & 0.03 & ns \\
$21 /$ SNA-SNP & 0.16 & ns \\
$R^{2}=0.54065844 ; R^{2}$ correct $=0.38754459$ & & \\
\hline
\end{tabular}

TABLE 8: Group 2 (17 subjects): linear regression results OJ-1. ANB and 21/SNA-SNP were found to be statistically significant. The systematic error calculated via Student's $t$-test for paired data yielded a significance level of 0.05 ; ns: non significant (Student's $t$ test).

\begin{tabular}{lcc}
\hline & $B$ & $P$ level \\
\hline ANB & 1.04 & 0.006044 \\
$11 /$ SNA-SNP & -0.04 & $\mathrm{~ns}$ \\
IMPA SX & -0.05 & $\mathrm{~ns}$ \\
21/SNA-SNP & 0.22 & 0.03702 \\
$R^{2}=0.18725388 ; R^{2}$ correct $=0.02470466$ & & \\
\hline
\end{tabular}

significant, as was the intercept $(P=0.003348)$. The model can therefore be expressed as

$$
\text { OJ LEFT }=-22.03+1.05 * \text { ANB }+0.19 * 21 / \text { ANS-PNS. }
$$

The indicator of linear determination $R^{2}$ is high enough $\left(R^{2}=0.589\right)$ to validate the above model.

\section{Discussion}

Among the factors which must be evaluated to formulate a correct diagnosis and a suitable treatment plan, the anteroposterior relationship between the jaws is a particularly relevant parameter [7].

As proposed by the ABO (American Board of Orthodontist), overjet, in association with other parameters such as overbite, IMPA, presence of open bite or crossbite, or entity of crowding, is a useful indicator in evaluation of the diagnostic complexity [8].

The aim of this paper was to establish by what degree a dental parameter (overjet) is able to predict the entity of the skeletal parameter ANB and the dentoskeletal parameters IMPA and upper incisor-bispinal plane axis.

The sample in this study was constituted by subjects of the Dental Clinic of the University of Ferrara Postgraduate School in Orthodontics, all in integral permanent dentition, not treated orthodontically and not affected by systemic pathologies.

Subjects presenting skeletal class III were excluded as they were not present in a statistically significant number. This reflects the frequency of malocclusions present in the Italian population [9]. 
International Journal of Dentistry

The use of CBCT (cone-beam computed tomography) was further justified by the fact that the effective dose of radiation that the patient receives (56.2 milli Sv) is significantly lower than that emitted by traditional fan beam systems (CT multislice 429.7 milli Sv) and is similar to values discharged during orthopantomography or conventional teleradiography (10.4 milli Sv) [10, 11].

From analysis of the entire sample, it emerges that overjet, both left and right, was correlated in a statistically significant manner $(P<0.001)$ with ANB, despite the index of linear determination being rather low: in the first case (right side) $R^{2}=0.391$, and in the second (left side) $R^{2}=$ 0.313 . This was probably due to the fact that overjet is influenced by the inclination of the upper and lower incisors, while ANB also varies according to the anteroposterior position of the nasion [12], the inclination of the SN plane, and the inclination of the jaws [13]. Another factor able to modify the width of ANB, even if the relationship between the jaws remains constant, is the inclination of the occlusal plane [14].

In contrast, no correlation was revealed between overjet and IMPA, while a weak correlation emerged between overjet and left upper incisor-bispinal plane. This is likely to be due to the difficulty in establishing the position of the incisors with respect to the osseous base with a sufficient degree of reliability, as the dentoalveolar values are subject to greater compensatory variations $[15,16]$.

From the analysis of the two distinct groups, different results were obtained. Regarding skeletal first class subjects, it was not possible to formulate any type of correlation, neither on the left nor the right, between overjet and the other variables examined. This can be explained by the fact that skeletal class I subjects are generally less "harmonic," that is, exposed to a greater number of compensatory variations, in both sagittal and vertical directions, sufficient to render the creation of a mathematical model able to predict their entity impossible [17-19].

Concerning skeletal class II on the other hand, it was possible to construct, for the left side, a good model to correlate overjet and ANB, characterised by a high significance value $(P=0.002990)$ and a good linear determination index $R^{2}=0.589$. Analogous to that revealed for the entire sample, no correlation with the IMPA and only a slight correlation with the left upper incisor-bispinal plane was determined.

In the study conducted by Zupancic et al. in exclusive class II subjects, the overjet was found to be "a statistically significant predictor of the skeletal relationship in the sagittal plane" [19]. However, in our study, it was not possible to construct a statistically significant model for the right-hand side. The difference between the two sides has no precise justification but is probably linked to the low number of test subjects in the sample.

In contrast to previous studies performed on conventional teleradiographs, the present study offers the advantage of analysing precisely and accurately the anatomical structures both from the left side and from the right, thereby permitting radiographic artefacts, superimpositions, and flaws produced by an inevitable and omnipresent asymmetry of the face to be eliminated [20,21].

\section{Conclusions}

The results of the study conducted on the entire sample indicate how a dental parameter such as overjet can be a reliable predictor of ANB angle, and to a lesser extent the U1bispinal plane. No significant data were revealed concerning IMPA.

However, if the cases of skeletal class I and class II are considered separately, different results are obtained. In fact, in the cases of skeletal class I (Group 1), it was not possible to establish a correlation between the variables analysed. In contrast, the class II cases reflected the entire sample in that OJ left was found to predict both ANB angle and 21/ANSPNS to a sufficient degree, despite not being in correlation with IMPA.

\section{References}

[1] W. R. Proffit and J. L. Ackerman, "Orthodontic diagnosis: the development of a problem list," in Contemporary Orthodontics, W. R. Proffit and H. W. Fields, Eds., pp. 145-1293, Mosby, St. Louis, Mo, USA, 3rd edition, 2000.

[2] J. E. Harrison, K. D. O'Brien, and H. V. Worthington, "Orthodontic treatment for prominent upper front teeth in children," Cochrane Database of Systematic Reviews, vol. 18, no. 3, Article ID CD003452, 2007.

[3] W. R. Proffit et al., Contemporary Orthodontics, chapter 1, Mosby, St. Louis, Mo, USA, 2nd edition, 1993.

[4] W. Hussels and R. S. Nanda, "Analysis of factors affecting angle ANB," American Journal of Orthodontics, vol. 85, no. 5, pp. 411-423, 1984.

[5] C. C. Steiner, "The use of cephalometrics as an aid to planning and assessing orthodontic treatment. Report of a case," American Journal of Orthodontics, vol. 46, no. 10, pp. 721-735, 1960.

[6] A. Gracco, L. Lombardo, and M. P. Guarneri, La Tomografia Volumetrica Digitale, Edizioni Martina.

[7] J. L. Tanaka, E. Ono, E. Filho Medici, L. Cesar de Moraes, J. Cezar de Melo Castilho, and M. E. Leonelli de Moraes, "Influence of the facial pattern on ANB, AF-BF, and Wits appraisal," World Journal of Orthodontics, vol. 7, no. 4, pp. 369-375, 2006.

[8] T. J. Cangialosi, M. L. Riolo, S. E. Owens et al., "The ABO discrepancy index: a measure of case complexity," American Journal of Orthodontics and Dentofacial Orthopedics, vol. 125, no. 3, pp. 270-278, 2004.

[9] G. Perinetti, C. Cordella, F. Pellegrini, and P. Esposito, "The prevalence of malocclusal traits and their correlations in mixed dentition children: results from the Italian OHSAR Survey," Oral Health \& Preventive Dentistry, vol. 6, no. 2, pp. 119-129, 2008.

[10] M. A. G. Silva, U. Wolf, F. Heinicke, A. Bumann, H. Visser, and E. Hirsch, "Cone-beam computed tomography for routine orthodontic treatment planning: a radiation dose evaluation," American Journal of Orthodontics and Dentofacial Orthopedics, vol. 133, no. 5, pp. 640.e1-640.e5, 2008.

[11] J. Huang, A. Bumann, and J. Mah, "Three-dimensional radiographic analysis in orthodontics," JCO, vol. 39, no. 7, pp. 421428, 2005.

[12] G. Ferrazzini, "Critical evaluation of the ANB angle," American Journal of Orthodontics, vol. 69, no. 6, pp. 620-626, 1976. 
[13] S. E. Bishara, J. A. Fahl, and L. C. Peterson, "Longitudinal changes in the ANB angle and Wits appraisal: clinical implications," American Journal of Orthodontics, vol. 84, no. 2, pp. 133-139, 1983.

[14] M. Del Santo, "Influence of occlusal plane inclination on ANB and Wits assessments of anteroposterior jaw relationships," American Journal of Orthodontics and Dentofacial Orthopedics, vol. 129, no. 5, pp. 641-648, 2006.

[15] H. Ishikawa, S. Nakamura, H. Iwasaki, S. Kitazawa, H. Tsukada, and Y. Sato, "Dentoalveolar compensation related to variations in sagittal jaw relationships," Angle Orthodontist, vol. 70, no. 2, pp. 145-148, 2000.

[16] B. Baydaş, I. Yavuz, I. M. Dağsuyu, B. Bölükbaşi, and I. Ceylan, "An investigation of maxillary and mandibular morphology in different overjet groups," Australian Orthodontic Journal, vol. 20, no. 1, pp. 11-18, 2004.

[17] M. Milacic and M. Markovic, "A comparative occlusal and cephalometric study of dental and skeletal anteroposterior relationships," British Journal of Orthodontics, vol. 10, no. 1, pp. 53-54, 1983.

[18] I. Ceylan, I. Yavuz, and F. Arslan, "The effects of overjet on dentoalveolar compensation," European Journal of Orthodontics, vol. 25, no. 3, pp. 325-330, 2003.

[19] S. Zupančič, M. Pohar, F. Farčnik, and M. Ovsenik, "Overjet as a predictor of sagittal skeletal relationships," European Journal of Orthodontics, vol. 30, no. 3, pp. 269-273, 2008.

[20] M. F. Steinke and E. Bezak, "Technological approaches to inroom CBCT imaging," Australasian Physical and Engineering Sciences in Medicine, vol. 31, no. 3, pp. 167-179, 2008.

[21] O. J. C. van Vlijmen, S. J. Bergé, G. R. J. Swennen, E. M. Bronkhorst, C. Katsaros, and A. M. Kuijpers-Jagtman, "Comparison of cephalometric radiographs obtained from cone-beam computed tomography scans and conventional radiographs," Journal of Oral and Maxillofacial Surgery, vol. 67, no. 1, pp. 92-97, 2009. 


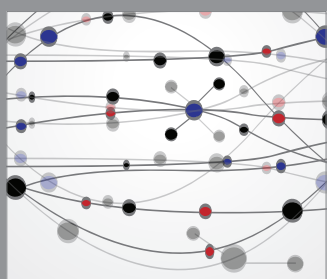

The Scientific World Journal
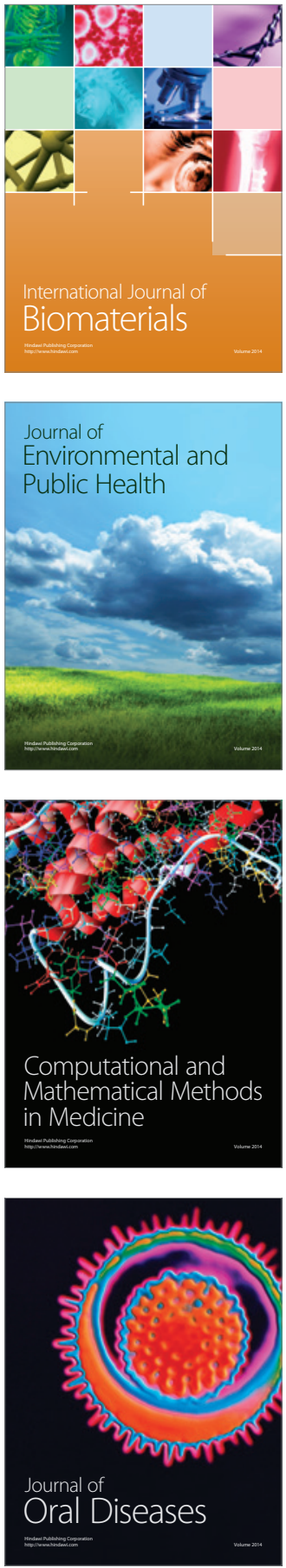
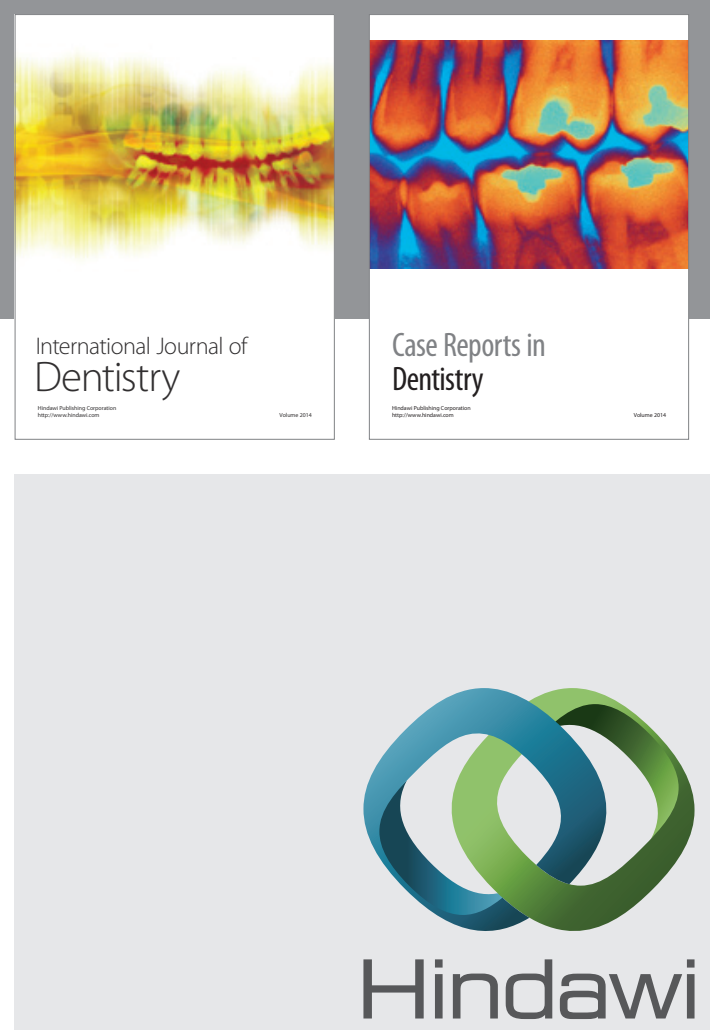

Submit your manuscripts at

http://www.hindawi.com
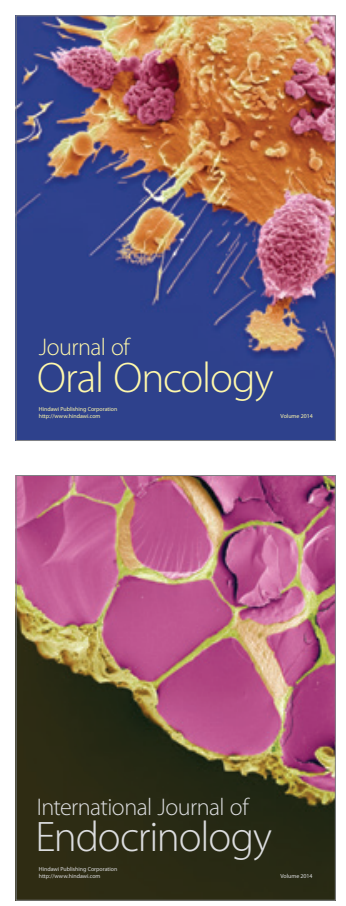
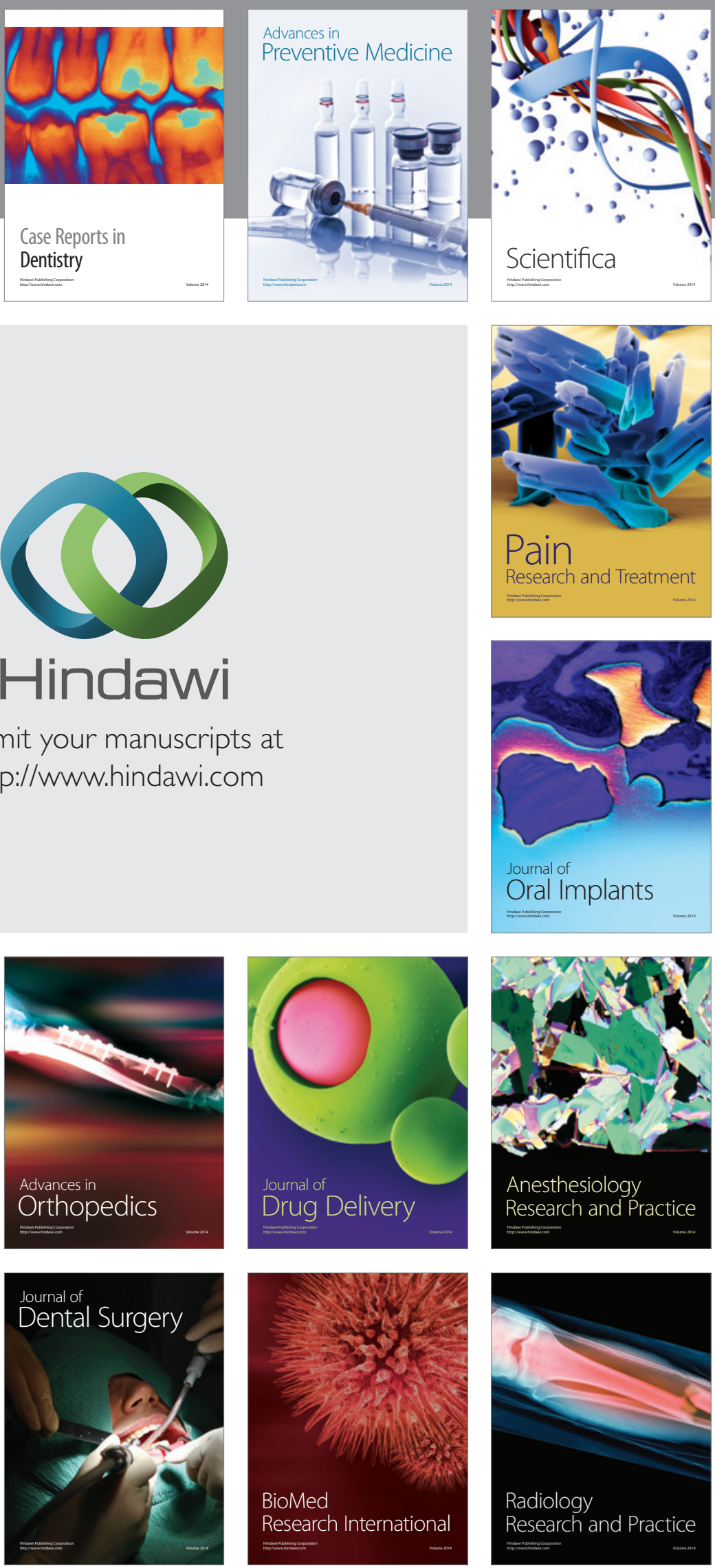